DOI: $10.21767 / 2471-8505.100013$

\section{OEIS Complex, A Case Report}

\section{Abstract}

Introduction: The OEIS complex includes: Omphalocele, Exstrophy of the cloaca, Imperforate anus, and Spinal defects. The OEIS complex affects 1 in 200,000 to 400,000 pregnancies and its etiology is uncertain. The purpose is to present our experience in this unusual coexistence of malformations never reported in Latin America.

Clinical Case: A male infant, three months of age, diagnosed at birth with omphalocele, cloacal exstrophy, double hemi bladder, rectum and anal atresia, bilateral clubfeet and lumbosacral bifid spine. Abdominal MRI confirmed clinical findings and also showed horseshoe kidney, bilateral enlarged renal pelvis. Lumbosacral spine MRI revealed lipomeningocele, hypoplastic sacrum and pubic agenesia. In the first two days of life, this patient underwent several surgical procedures. Currently ( 3 months old) is waiting for further surgical reconstruction.

Conclusion: The case described meets the clinical criteria for OIES complex; in the absence of a family history that could suggest a pattern of Mendelian inheritance and normal cytogenetic study. We conclude that this is an isolated case of probable multifactorial inheritance.

Patients require immediate postnatal multidisciplinary care, surgical management is recommended in the neonatal period, using a multi-stage approach to reconstructive surgery and follow-up throughout life.

Keywords: Omphalocele exstrophy imperforate anus; Bladder exstrophy; Spine/ abnormalities

\section{Manassero-Morales G, Franco-Bustamante $\mathrm{K}_{\text {, }}$ Matos-Rojas I}

\author{
National Institute of Child Health, San Borja, \\ Lima, Perú
}

\section{Corresponding author:}

Manassero-Morales G

\section{Manassero.gioconda@gmail.com}

Instituto Nacional de Salud del Niño-San Borja, Lima, Perú

Citation: Manassero-Morales G, FrancoBustamante K, Matos-Rojas I .OEIS Complex, A Case Report. J Intensive \& Crit Care 2016, $2: 1$.

\section{Case Details}

We report a case of a newborn, male, first child, born in Huancayo, Peru, non-consanguineous parents (Figure 1). At term, vaginal delivery, examination at birth evidenced omphalocele and cloacae exstrophy. The baby was referred to the Neonatal Intensive Care Unit (NICU) at the National Institute of Child Health - San Borja, Lima, Peru, for surgical management.

Clinical examination at the NICU (age: two days) showed weight 2505g, height $45 \mathrm{~cm}$, heart rate 175-180 beats/minute, respiratory rate $45 / \mathrm{min}$, microcephaly (head circumference: 31 $\mathrm{cm}$, under third percentile), normotensive fontanelle, non-facial dysmorphia. Cardiovascular: systolic murmur III/VI. Abdomen and pelvis: absence of abdominal wall, exposed bowel loops partially covered by the omphalocele membrane. Cloacal exstrophy, rectum and anal atresia. Skeletal: Bilateral clubfeet, lumbosacral bifid spine. Genital: External genitalia absent and non-detected gonads. Hypotonia and lower limbs arreflexia (Figures $\mathbf{2}$ and $\mathbf{3}$ ).

Abdominal and pelvic MRI showed omphalocele, extrophy of double hemibladder, adjacent gonads, horseshoe kidney, bilateral enlarged renal pelvis.

Lumbosacral spine MRI revealed lipomeningocele, hypoplasic sacrum and pubis agenesia (Figure 4).

Cardiological ultrasonography found an atrial septal defect (ASD) of $1.9 \mathrm{~mm}$ and persistant arterious ductus (3.3 $\mathrm{mm}$ ).

The cytogenetic study was normal: 46, XY. Chorionic gonadotropin stimulation test was reactive.

In the first two days of life, this patient underwent the following surgical procedures: Laparotomy with intestinal individualization and intestinal raffia, colostomy, bladder partial union, pericardial patch placement. Currently is waiting for further surgical reconstruction. 


\section{Discussion}

OEIS complex was first described in 1978 by Carey et al, is the acronym for "Omphalocele", "Cloacal Exstrophy", "Imperforate anus", and "Spinal defects" [1].

Historically, the incidence for this complex is estimated in about 1 in 200,000 to 400,000 births, but multicenter epidemiological studies described a lower prevalence than the expected and reports that varies according to geographical location [2].

The clinical presentation is variable, with a wide spectrum of systemic involvement between patients, often presenting abnormalities of the gastrointestinal tract, genitourinary and skeletal system. Cardiovascular and neurological system affection is unusual $[3,4]$ (Table 1).

The diagnosis is evident at birth; auxiliary imaging tests are recommended in order to determine the nature and extent of associated malformations.

Prenatal diagnosis is possible from ultrasound findings (the main criteria are: no display of the bladder, front wall defects, omphalocele and myelomeningocele). Fetal MRI is also useful $[5,6]$

Table 1 Abnormalities of the gastrointestinal tract, genitourinary, skeletal system, cardiovascular and neurological system.

\begin{tabular}{|c|c|c|}
\hline CATEGORY & SUBCATEGORY & FEATURES \\
\hline Cardiovascular & Heart & $\begin{array}{l}\text { Persistent Ductus arteriosum } \\
\text { Oval foramen persistence }\end{array}$ \\
\hline \multirow[t]{2}{*}{ Abdomen } & Abdominal wall & Onphalocele \\
\hline & Gastrointestinal tract & $\begin{array}{c}\text { Imperforate anus } \\
\text { Duplication doubled colon or colon } \\
\text { Malrotation/ Intestinal atresia } \\
\text { Anal atresia } \\
\text { Rectal prolapse } \\
\text { Rectovaginal fistula }\end{array}$ \\
\hline \multirow[t]{7}{*}{ Genitourinary } & External genitalia (Male: $46, \mathrm{XY}$ ) & $\begin{array}{l}\text { Ambiguous genitalia } \\
\text { Small penis } \\
\text { Epispadias } \\
\text { Scrotum abnormal or absent }\end{array}$ \\
\hline & External genitalia (Female: $46, \mathrm{XX}$ ) & $\begin{array}{c}\text { Ambiguous genitalia } \\
\text { Labioscrotal widely spaced pleats. } \\
\text { Hypoplastic lips } \\
\text { Bifid clitoris }\end{array}$ \\
\hline & Internal genitalia (Male) & Cryptorchidism \\
\hline & Internal Genital (Female) & $\begin{array}{l}\text { Bifid or absent Uterus } \\
\text { Hypoplasia of the fallopian tubes }\end{array}$ \\
\hline & Kidneys & $\begin{array}{l}\text { Kidney hydronephrosis } \\
\text { Renal agenesis } \\
\text { Pelvic kidney }\end{array}$ \\
\hline & Ureters & $\begin{array}{l}\text { Duplicated ureters collector system } \\
\text { Hydroureter }\end{array}$ \\
\hline & Bladder & $\begin{array}{l}\text { Cloacal exstrophy } \\
\text { Hemibladder } \\
\text { VesicoVaginal Fistula }\end{array}$ \\
\hline \multirow[t]{4}{*}{ Skeletal } & Ribs, sternum, clavicle and scapula & 11 pairs of ribs \\
\hline & Spine & $\begin{array}{c}\text { Hemivertebrae } \\
\text { Absent or hypoplastic sacrum } \\
\text { Segmentation defects of the sacrum }\end{array}$ \\
\hline & Pelvis & $\begin{array}{l}\text { Diastasis of the pubic symphysis } \\
\text { Congenital hip dislocation }\end{array}$ \\
\hline & Limbs & $\begin{array}{c}\text { Clubfeet } \\
\text { Arthrogryposis } \\
\text { Syndactyly } \\
\text { Hypoplastic thumbs } \\
\text { Hypoplastic lower limbs }\end{array}$ \\
\hline Neurological & Central Nervous System & $\begin{array}{c}\text { Tethered cord } \\
\text { Lipomielocistocele } \\
\text { Myelomeningocele } \\
\text { Arnold Chiari } \\
\text { Hydrocephalus } \\
\text { Psychomotor retardation }\end{array}$ \\
\hline
\end{tabular}




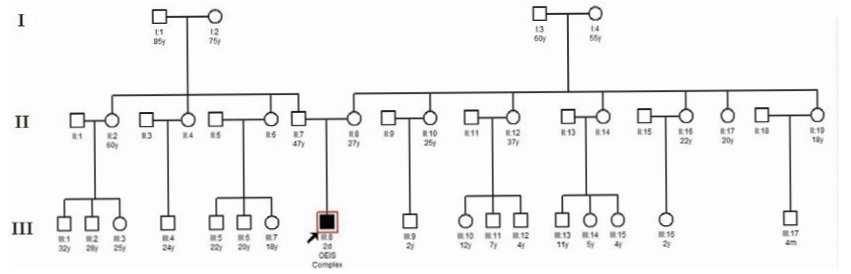

Figure 1 Family tree.

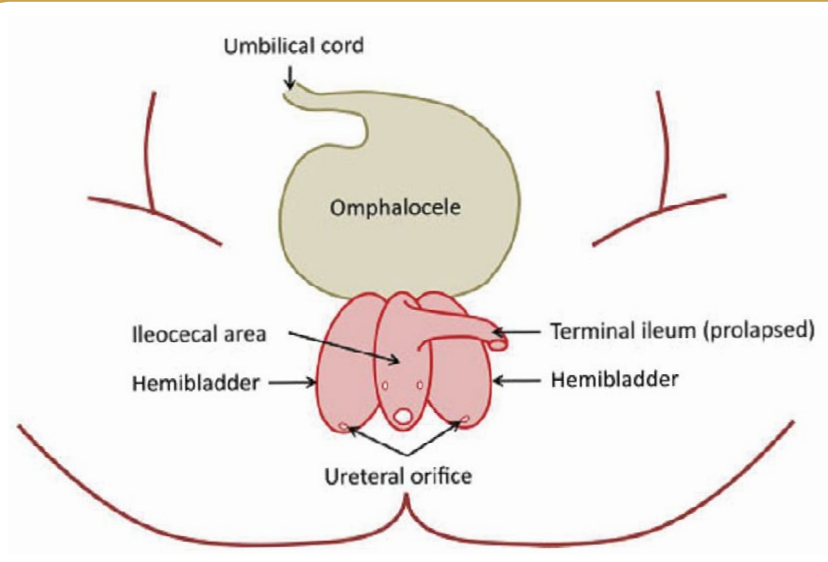

Figure 2 Onphalocele and cloacal exstrophy diagram.
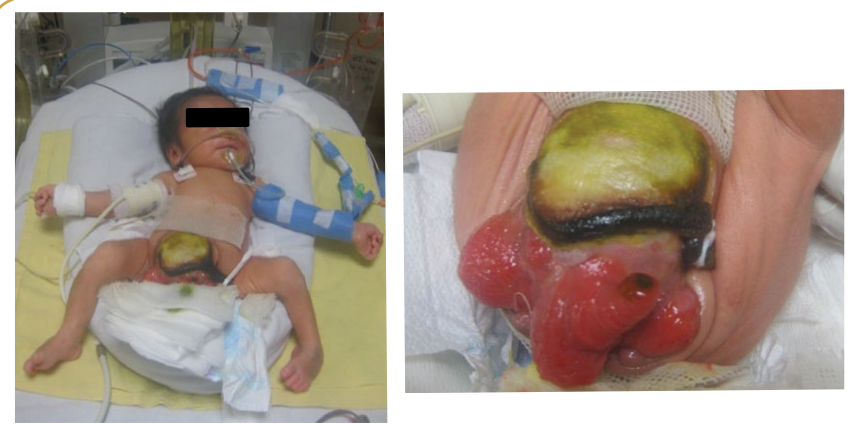

Figure 3 (a) Newborn, 2 days of age with OEIS complex. (b) Note omphalocele with cloacal exstrophy, absence of anus and external genitalia, clubfeet and global hypotonia.

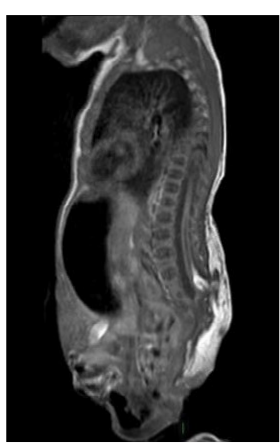

Figure 4 Spine MRI: Lipomeningocele.
Although most cases are sporadic, familial cases have been reported: two cases in subsequent pregnancies and a higher incidence of this disease in monozygotic twins were described [7-9].

The OEIS complex has been reported in association with chromosomal abnormalities such as Trisomy 18, 21, mosaic Turner, unbalanced translocation between chromosome 9 and the $Y$ chromosome, deletion of chromosome 3 (q12.2-q13.2) and deletion 1p36. Mosaicism in fibroblast culture was described in a patient with Ito Hypomelanosis and OIES complex $[9,10]$.

In 2010, a group of 14 patients with this pathology were studied microarrays and sequencing of 14 candidate genes, the study revealed no disease-causing mutations, CNVs reported in 7p15.1 and 17q21.31-q21. 32, 38 SNPS already described al genome database, and 10 new SNPs, supporting genetic complexity from an etiological perspective; it is likely to involve a combination of genetic and environmental predispositions [11].

There have been several possible embryologic mechanisms raised for these findings including: a single defect of blastogenesis where there is a single localized defect in the early caudal mesoderm at approximately 29 days of development, or a defect of mesodermal migration during the primitive streak period. In particular, there may be failure of cloacal septation with persistence of the cloaca, rudimentary mid-gut, and imperforate anus; failure of cloacal membrane breakdown leading to exstrophy of the cloaca, omphalocele, and lack of fusion of the pubic rami; and abnormal vertebrae resulting from abnormal somite formation [4].

The case described meets the clinical criteria for OIES complex; in the absence of a family history that could suggest a pattern of Mendelian inheritance and normal cytogenetic study. We conclude that this is an isolated case of probably multifactorial inheritance.

Patients require immediate postnatal multidisciplinary care, surgical management is recommended in the neonatal period, using a multi-stage approach to reconstructive surgery and follow-up throughout life [12].

Surgical advances and improvement in neonatal care have led to an improved quality of life and in a dramatic increase in survival rates. There are reports of patients up to 20 years of age $[11,12]$. 


\section{References}

1 Carey JC, Greenbaum B, Hall BD (1978) The OEIS complex (omphalocele, exstrophy, imperforate anus, spinal defects). Birth Defects Orig Artic Ser 14: 253-263.

2 Feldkamp ML, Botto LD, Amar E, Bakker MK, Bermejo-Sánchez E, et al. (2011) Cloacal exstrophy: An epidemiologic study from the International Clearinghouse for Birth Defects Surveillance and Research. Am J Med Genet C Semin Med Genet 157: 333-343.

3 OMIM Entry - 258040 - OEIS COMPLEX (2015) Omphalocele-ExstrophyImperforate Anus-Spinal Defects.

4 Keppler-Noreuil KM (2001) OEIS complex (omphalocele-exstrophyimperforate anus-spinal defects): A review of 14 cases. Am J Med Genet 99: 271-279.

5 Keppler-Noreuil K, Gorton S, Foo F, Yankowitz J, Keegan C (2007) Prenatal ascertainment of OEIS complex/cloacal exstrophy-15 new cases and literature review. Am J Med Genet A 143: 2122-2128.

6 Goto S, Suzumori N, Obayashi S, Mizutani E, Hayashi Y, et al. (2012) Sugiura-Ogasawara M. Prenatal findings of omphalocele-exstrophy of the bladder-imperforate anus-spinal defects (OEIS) complex. Congenit Anom 52: 179-181.

7 Smith NM, Chambers HM, Furness ME, Haan EA (1992) The OEIS complex (omphalocele-exstrophy-imperforate anus-spinal defects): recurrence in sibs. J Med Genet 29: 730-732.

8 Lee DH, Cottrell JR, Sanders RC, Meyers CM, Wulfsberg EA, et al. (1999) OEIS complex (omphalocele-exstrophy-imperforate anusspinal defects) in monozygotic twins. Am J Med Genet 84: 29-33.

9 Ludwig M, Ching B, Reutter H, Boyadjiev SA (2009) Bladder exstrophyepispadias complex. Birt Defects Res A Clin Mol Teratol 85: 509-522.

10 El-Hattab AW, Skorupski JC, Hsieh MH, Breman AM, Patel A, et al. (2010) OEIS complex associated with chromosome 1p36 deletion: A case report and review. Am J Med Genet A 152: 504-511.

11 Vlangos CN, Siuniak A, Ackley T, van Bokhoven H, Veltman J, et al. (2011) Comprehensive genetic analysis of OEIS complex reveals no evidence for a recurrent microdeletion or duplication. Am J Med Genet A 155: 38-49.

12 Ebert A-K, Reutter H, Ludwig M, Rösch WH (2009) The Exstrophyepispadias complex. Orphanet J Rare Dis 4: 23. 